\title{
Analysis of genetic diversity among Chinese wild Vitis species revealed with SSR and SRAP markers
}

\author{
Z.B. Jing ${ }^{1,2,3}$, X.P. Wang ${ }^{2,3}$ and J.M. Cheng ${ }^{1}$ \\ ${ }^{1}$ College of Animal Science and Technology, Northwest A\&F University, \\ Yangling, Shaanxi, China \\ ${ }^{2}$ College of Horticulture, Northwest A\&F University, \\ Key Laboratory of Horticultural Plant Biology and Germplasm Innovation in \\ Northwest China, Ministry of Agriculture, Yangling, China \\ ${ }^{3}$ State Key Laboratory of Crop Stress Biology in Arid Areas, \\ Northwest A\&F University, Yangling, Shaanxi, China \\ Corresponding author: X.P. Wang \\ E-mail: wangxiping@nwsuaf.edu.cn
}

Genet. Mol. Res. 12 (2): 1962-1973 (2013)

Received November 30, 2012

Accepted March 30, 2013

Published June 13, 2013

DOI http://dx.doi.org/10.4238/2013.June.13.5

ABSTRACT. The genetic diversity among 80 Vitis materials including
62 indigenous accessions of 17 wild Vitis species in China and 7
interspecific hybrids, $10 \mathrm{~V}$. vinifera L. cultivars, and $1 \mathrm{~V}$. riparia
Michaux were evaluated by simple sequence repeat and sequence-
related amplified polymorphism markers. A total of 10 simple sequence
repeat primers and 11 sequence-related amplified polymorphism primer
combinations were amplified, and 260 bands were generated, of which
252 were polymorphic with an average polymorphism rate of $97.02 \%$.
Genetic relationships among the different Vitis species indicated that $V$.
ficifolia and $V$. yeshanensis could be considered a separate species. As
for the 4 major ecogeographic regions of Chinese wild Vitis species,
the genetic diversities of Chinese wild Vitis species from the Qinling
Mountain region $(H=0.1947, I=0.3067)$ and the mid-downstream 
Yangtze River region $(H=0.1834, I=0.2925)$ were higher, with results suggesting that these regions may be one of the major centers of Vitis origin. An understanding of the genetic diversity of these Chinese wild Vitis species could provide the theoretical foundation for further protection and reasonable utilization in grape breeding.

Key words: Chinese wild grape; Vitis; Genetic diversity; SSR; SRAP

\section{INTRODUCTION}

Grape (Vitis vinifera L.) is one of the most important fruit crop in the world, and grows in South Europe, Asia Minor, East Asia, and North and Central America (Wan et al., 2008). There are more than 70 Vitis species, mainly distributed in the Northern Hemisphere (Ercisli et al., 2008).

China is one of the major germplasm gene centers of Vitis species origination. More than 35 Vitis species have their origin in China (Wan et al., 2008). Chinese wild Vitis species have many excellent characteristics, including 1 ) high-quality wine-making attributes, such as high sugar content and moderate acidity ( $\mathrm{Li}$ and $\mathrm{He}, 2000) ; 2$ ) a high level of resistance to fungal diseases, including powdery mildew [Uncinula necator (Schw.) Burr.], anthracnose [Elsinoë ampelina (de Barry) Shear], ripe rot [Glomerella cingulata (Ston.) Spauld and Schrenk], and crown gall [Agrobacterium tumefaciens Smith and Townsend] (He et al., 1991; Wang et al., 1995, 2007); 3) highly efficient photosynthesis in $V$. quinquangularis (Zhu et al., 1994); and 4) the facts that Chinese wild Vitis can be easily crossed with American Vitis species, and the undesirable "foxy" flavor compounds in the berries of American Vitis species are nonexistent in Chinese wild Vitis species (He, 1999b; Wan et al., 2008).

Up to now, selection for the desirable characteristics of Chinese wild grape has enlarged the scope of applications for grape breeding. This has resulted in many intermediate and transitional types of Vitis, which cause difficulties in germplasm research of the wild Chinese Vitis. Moreover, the classification of a few Chinese Vitis species adopted by Chinese taxonomists has led to some controversy and confusion, and further studies are necessary to classify and elucidate the evolutionary relationships between the various Vitis species. In previous studies, the taxonomy and germplasm identification of some wild Vitis species natives to China have been completed based on morphological and isoenzyme approaches (He et al., 1996; Niu and He, 1996; Ma and He, 1998). However, the morphological characteristics and isoenzymes of grapes are easily affected by the developmental period and the environment (Luo et al., 2001). DNA molecular marker technologies are available for the analysis of genetic diversity at the DNA level. A few studies applying random amplified polymorphic DNA (RAPD), sequence-related amplified polymorphism (SRAP), and start codon targeted techniques have reported the use of DNA markers to classify and analyze the genetic relationships between and within Chinese wild grape, and foreign cultivars (Luo et al., 2001; Guo et al., 2012a,b). So far, there are no reports to assess the genetic diversity and relationships for more than 18 Chinese wild Vitis species by combination of simple sequence repeat (SSR) and SRAP markers. Two technologies, SSR and SRAP, are recognized as being the most used molecular markers because they are simple, reliable, and effective (Guo et al., 2012b).

In this study, we combined SSR and SRAP markers to analyze the genetic diversity and relationships among wild Vitis species native to China, America, and European cultivars from different ecogeographic regions in China. Our studies will facilitate the efficient evalua- 
tion, conservation, management, and utilization of Chinese wild grape germplasm resources.

\section{MATERIAL AND METHODS}

\section{Plant materials}

A total of 80 Vitis materials including 62 clones of 17 wild Vitis species native to China, and 7 interspecific hybrids, 10 European cultivars, and 1 V. riparia Michaux were collected from the orchard of grape germplasm resources, Northwest A\&F University, Yangling, Shaanxi, China. The 62 wild grapes were from 4 ecogeographic regions in China. Information for the 80 Vitis materials is listed in Table 1. Young healthy leaves from plants of each accession were collected and stored under $-80^{\circ} \mathrm{C}$ for later DNA extraction.

\begin{tabular}{|c|c|c|c|c|c|c|c|c|c|}
\hline Species & $\begin{array}{l}\text { Pop. } \\
\text { code }\end{array}$ & $\begin{array}{l}\text { Code } \\
\text { No. }\end{array}$ & Clones & Origin & Species & $\begin{array}{l}\text { Pop. } \\
\text { code }\end{array}$ & $\begin{array}{l}\text { Code } \\
\text { No. }\end{array}$ & Clones & Origin \\
\hline V.pseudoreticulata & $\mathrm{A}$ & 1 & Baihe-13-1 & $\mathrm{R} 4$ & & & 41 & Liu-9 & \\
\hline W.T. Wang & & 2 & Guangxi-2 & & & & 42 & Baishui-40 & \\
\hline \multirow[t]{9}{*}{ V. amurensis Rupr. } & B & 3 & Zuoshan-75079 & R1 & V. davidii (Roman) & I & 43 & Tangwei & $\mathrm{R} 3$ \\
\hline & & 4 & Taishan-11 & & Foex & & 44 & Fujian-4 & \\
\hline & & 5 & Zuoshan-2 & & & & 45 & Xuefeng & \\
\hline & & 6 & Zuoshan-1 & & & & 46 & Lueyang-4 & \\
\hline & & 7 & Heilongjiang $\widehat{\partial}$ & & & & 47 & Ningqiang-6 & \\
\hline & & 8 & Tonghua-3 & & V. adstricta Hance & $\mathrm{J}$ & 48 & Taishan-1 & R3 \\
\hline & & 9 & Shuangyou & & & & 49 & Taishan-2 & \\
\hline & & 10 & Zuoshan-76097 & & & & 50 & Taishan-1 & \\
\hline & & 11 & Zuoshan-12 & & & & 51 & Anlin-3 & \\
\hline V. baihensis L.X. Niu & $\mathrm{C}$ & 12 & Baihe-40 & R3 & & & 52 & Anlin-2 $\delta$ & \\
\hline V. bashanica P.C. He & $\mathrm{D}$ & 13 & Baihe-41 & $\mathrm{R} 2$ & V. hancockii Hance & $\mathrm{K}$ & 53 & Jiangxi-3 & R3 \\
\hline \multirow[t]{2}{*}{ V. liubaensis L.X. Niu } & $\mathrm{E}$ & 14 & Langao-2 & R3 & & & 54 & Jiangxi-3 $\widehat{\partial}$ & \\
\hline & & 15 & Liu-10 & & V. qinlingensis P.C. $\mathrm{He}$ & $\mathrm{L}$ & 55 & Pingli-5 & $\mathrm{R} 2$ \\
\hline V. quinquangularis & $\mathrm{F}$ & 16 & Weinan-3 & $\mathrm{R} 2$ & & & 56 & Lueyang-4 & \\
\hline \multirow[t]{7}{*}{ Rehd. } & & 17 & 83-4-94우 & & V. yeshanensis J.X. Chen & M & 57 & Yanshan-1 & $\mathrm{R} 2$ \\
\hline & & 18 & $83-4-96$ 早 & & V. ficifolia Bunge. & $\mathrm{N}$ & 58 & Sangye & $\mathrm{R} 2$ \\
\hline & & 19 & Shang-24 & & $V . \operatorname{spp}$ (Qiufuyie) & $\mathrm{O}$ & 59 & Meixian-6 & $\mathrm{R} 1$ \\
\hline & & 20 & $83-4-49$ ㅇ & & & & 60 & Liu-7 & \\
\hline & & 21 & $83-4-49$ & & V. riparia Michaux & $\mathrm{P}$ & 61 & Hean-3 & US \\
\hline & & 22 & Dan-2 & & $\begin{array}{l}\text { Interspecific hybrid } \\
\text { (V. binifera } \times \text { V. labrusca })\end{array}$ & Q & 62 & Tengnian & \\
\hline & & 23 & Huaxian-11 & & & & 63 & Early-Takasumi & \\
\hline \multirow[t]{12}{*}{ V. romanetii Roman. } & G & 24 & Jiangxi-2 & $\mathrm{R} 3$ & & & 64 & Jingya & \\
\hline & & 25 & Pingli-2 & & & & 65 & Kyoho & \\
\hline & & 26 & Pingli-2 3 & & & & 66 & Jingyou & \\
\hline & & 27 & Jiangxi-1(green) & & & & 67 & Hutai-8 & \\
\hline & & 28 & Jiangxi-1(green) & & & & 68 & Campbell Early & \\
\hline & & 29 & Jiangxi-2(red) & & $V$ vinifera $\mathrm{L}$. & $\mathrm{R}$ & 69 & Merlot & \\
\hline & & 30 & Liuba-11 & & & & 70 & White Riesling & \\
\hline & & 31 & Jiangxi-1(red) $q$ & & & & 71 & Chardonnay & \\
\hline & & 32 & Jiangxi-2(red) & & & & 72 & Early-Rose & \\
\hline & & 33 & Pingli-7 & & & & 73 & Italian Riesling & \\
\hline & & 34 & Baihe-22 & & & & 74 & Jingxiu & \\
\hline & & 35 & Liuba-1 & & & & 75 & Christmas Rose & \\
\hline \multirow[t]{5}{*}{ V. piasekii Maxim } & $\mathrm{H}$ & 36 & Nanzheng-2 & $\mathrm{R} 2$ & & & 76 & Carignane & \\
\hline & & 37 & Gansu-91 & & & & 77 & Pinot Noir & \\
\hline & & 38 & Gansu-91오 & & & & 78 & Princes seedless & \\
\hline & & 39 & Liu- 8 & & Vitis sp & $\mathrm{S}$ & 79 & Bianye & R4 \\
\hline & & 40 & Liu-6 & & Unknown & $\mathrm{T}$ & 80 & Wanxian-15 & R3 \\
\hline
\end{tabular}

R1, R2, R3, R4 = 4 major ecogeographic regions of Chinese wild grape distribution. R1 = Changbaishan and Xiaoxing'anling Mountain regions; R2 = Qinling Mountain region; R3 = Yangtze River region; R4 = Guangxi region. 


\section{DNA extraction}

Genomic DNA was extracted from fresh leaves using a modification of the hexadecyltrimethylammonium bromide method described by Qu et al. (1996), and the quality was tested by $0.8 \%(\mathrm{w} / \mathrm{v})$ agarose gel electrophoresis. DNA concentrations were determined with a UV-VIS spectrophotometer, and samples were diluted to $40 \mathrm{ng} / \mu \mathrm{L}$ and then stored at $-20^{\circ} \mathrm{C}$ for PCR amplification.

\section{PCR amplification and electrophoresis}

A total of 10 SSR primers and 11 SRAP primer combinations were synthesized by Beijing Aoke Biological Technology and Service Co. Ltd. The SSR and SRAP primer sequences are listed in Table 2. For SSR analysis, each $20-\mu \mathrm{L}$ amplification reaction system consisted of $20 \mathrm{ng}$ template DNA, 10X PCR buffer (100 mM Tris-HCl, $\mathrm{pH} \mathrm{8.3,} \mathrm{and}$ $500 \mathrm{mM} \mathrm{KCl}$ ), $0.20 \mathrm{mM}$ each dNTP, $0.75 \mathrm{mM}$ each primer, $2.0 \mathrm{mM} \mathrm{MgCl}_{2}$, and $1 \mathrm{U} \mathrm{Taq}$ DNA polymerase. The PCR amplification was conducted under the following conditions: initial $5 \mathrm{~min}$ at $94^{\circ} \mathrm{C}$; followed by 35 cycles of $1 \mathrm{~min}$ at $94^{\circ} \mathrm{C}$, annealing at appropriate temperature for $1 \mathrm{~min}, 90 \mathrm{~s}$ extension at $72^{\circ} \mathrm{C}$; and a final extension of $8 \mathrm{~min}$ at $72^{\circ} \mathrm{C}$. The PCR amplification of SRAP markers was carried out in a $20-\mu \mathrm{L}$ volume, containing $20 \mathrm{ng}$ template DNA, 10X PCR buffer (100 mM Tris-HCl, $\mathrm{pH} 8.3,500 \mathrm{mM} \mathrm{KCl}), 0.18 \mathrm{mM}$ each dNTP, $0.75 \mathrm{mM}$ each primer, $1.87 \mathrm{mM} \mathrm{MgCl}_{2}$, and $1 \mathrm{U}$ Taq DNA polymerase. The PCRs were performed as follows: 5 min of denaturing at $94^{\circ} \mathrm{C}$ followed by 5 cycles of 3 steps: 1 min of denaturing at $94^{\circ} \mathrm{C}, 1 \mathrm{~min}$ of annealing at $35^{\circ} \mathrm{C}$, and 2 min of elongation at $72^{\circ} \mathrm{C}$. In the following 30 cycles, the annealing temperature was increased to $50^{\circ} \mathrm{C}$, with a final elongation step of $5 \mathrm{~min}$ at $72^{\circ} \mathrm{C}$.

The PCR products were separated on $6 \%$ denatured polyacrylamide gels and detected by silver staining. Then, clearly and reproducibly distinguished bands were recorded and used in the following analysis. The DL 2000 DNA ladder (TaKaRa Biotechnology Dalian Co., Ltd., China) was used as DNA markers.

\section{Data analyses}

After silver staining, each SRAP and SSR fragment was scored as present (1) or absent (0) for each of the 80 DNA samples, excluding the weak and blurred bands, thus generating a binary data matrix. The binary data matrix was analyzed using the NTSYSpc version 2.1e software package (Rohlf, 2000). The pairwise genetic distances among all accessions, according to Nei (1978), were calculated based on the Jaccard similarity coefficient. Cluster analyses (SSR + SRAP) were performed using the unweighted pairgroup method with arithmetic average (UPGMA). The dendrogram was constructed using the NTSYS-pc version 2.1 software package and MEGA version 4.0 (Tamura et al., 2007). The principal coordinate analysis (PCoA) was performed using the DCENTER and EIGEN programs in the NTSYS-pc version 2.1 software package. Finally, the observed number of alleles $\left(N_{\mathrm{A}}\right)$, effective number of alleles $\left(N_{\mathrm{E}}\right)$, Nei's gene diversity index $(H)$, and Shannon information index $(I)$ were calculated using POPGENE version 1.32 (Yeh et al., 1999). 


\section{RESULTS}

\section{Polymorphism analysis}

A total of 36 SSR primer pairs and 168 SRAP primer combinations were used to screen for polymorphism between 5 accessions from different species. Among them, 10 SSR primer pairs and 11 SRAP primer combinations amplified clear and abundant fragments, and were used to evaluate the genetic diversity of 80 Vitis accessions.

A total of 260 bands ranging from 200 to $2000 \mathrm{bp}$ were scored with an average of 12.38 bands per primer, of which $252(97.02 \%)$ were polymorphic. Each primer generated 5 (UDV-060) to $25(\mathrm{Me} 12+\mathrm{Em} 8)$ bands, and the percentage of polymorphic bands produced by each primer ranged from 85.71 to $100 \%$. The results of the SSR and SRAP analysis are listed in Table 2.

\begin{tabular}{|c|c|c|c|c|}
\hline Primer & $t$ & $p$ & $\mathrm{P} \%$ & Primer sequence \\
\hline VVMD15 & 15 & 15 & 100.00 & F: CTGCAGTGCACTCAAAGTTGG; R: TGAAACACCAAGGGAAACCTC \\
\hline VVMD19 & 11 & 10 & 90.91 & F: TGAAATATCATCAATGCTCTCTCTCC; R: GGTTGATATTGCTTCCTTTTCCC \\
\hline UDV-046 & 15 & 13 & 86.67 & F: CGTCATGGCTTCTGCTCAT; R: TGATACCACAGTCTGCTGATTTTT \\
\hline UDV-048 & 9 & 9 & 100.00 & F: CACTTGTGTGTGCAGTCCT; R: CTTTCCTCACCGAACACTC \\
\hline UDV-050 & 8 & 7 & 87.50 & F: TAATGGCCCCTTACAACACC; R: AGCTTCACTGCCAAAGGATG \\
\hline UDV-060 & 5 & 5 & 100.00 & F: CCTGCCACACCACAATACAA; R: TGGGGTAAAACTGGGTGTTT \\
\hline UDV-067 & 10 & 10 & 100.00 & F: TCATGGACTCACATCCTCAAA; R: TGAGTGGATGAAGGACAGTTC \\
\hline UDV-088 & 11 & 11 & 100.00 & F: CCATGCACACACGCACAT; R: CCACCAAACAAGTGGAGGTT \\
\hline VMC9a2.1 & 10 & 10 & 100.00 & F: AGCTCGGCTAGCTGCAAAATC; R: ACCCTTCCCTCTTCAAAACCC \\
\hline VMC7h3 & 11 & 11 & 100.00 & F: TCAGATATTGAAGAACACCACA; R: ACTAGAAAATGCACAATCTCCC \\
\hline $\mathrm{Me} 1+\mathrm{Em} 3$ & 13 & 13 & 100.00 & F: TGA GTC CAAACC GGATA; R: GAC TGC GTA CGA ATT GAC \\
\hline $\mathrm{Me} 2+\mathrm{Em} 5$ & 9 & 9 & 100.00 & F: TGA GTC CAA ACC GGAGC; R: GAC TGC GTA CGA ATT AAC \\
\hline $\mathrm{Me} 2+\operatorname{Em} 7$ & 16 & 15 & 93.75 & F: TGA GTC CAA ACC GGAGC; R: GAC TGC GTA CGA ATT CAA \\
\hline $\mathrm{Me} 2+\mathrm{Em} 3$ & 22 & 22 & 100.00 & F: TGA GTC CAA ACC GGAGC; R: GAC TGC GTA CGA ATT GAC \\
\hline $\mathrm{Me} 3+\mathrm{Em} 5$ & 14 & 12 & 85.71 & F: TGA GTC CAA ACC GGAAT; R: GAC TGC GTA CGA ATT AAC \\
\hline $\mathrm{Me} 3+\mathrm{Em} 3$ & 10 & 10 & 100.00 & F: TGA GTC CAA ACC GGAAT; R: GAC TGC GTA CGA ATT GAC \\
\hline $\mathrm{Me} 8+\mathrm{Em} 14$ & 13 & 13 & 100.00 & F: TGA GTC CAA ACC GGACT; R: GAC TGC GTA CGA ATT CTT \\
\hline $\mathrm{Me} 8+\mathrm{Em} 19$ & 10 & 10 & 100.00 & F: TGA GTC CAA ACC GGACT; R: GACTGCGTACG AATT TCA \\
\hline Me12+Em8 & 25 & 25 & 100.00 & F: TGA GTC CAA ACC GGAGA; R: GAC TGC GTA CGA ATT CAC \\
\hline $\mathrm{Me} 12+\mathrm{Em} 19$ & 14 & 13 & 92.86 & F: TGA GTC CAA ACC GGAGA; R: GACTGCGTACG AATT TCA \\
\hline $\mathrm{Me} 13+\mathrm{Em} 19$ & 9 & 9 & 100.00 & F: TGA GTC CAA ACC GGAAG; R: GACTGCGTACG AATT TCA \\
\hline Total & 260 & 252 & 2037.4 & \\
\hline Average & 12.38 & 12 & 97.02 & \\
\hline
\end{tabular}

$t=$ number of total loci; $p=$ number of polymorphic loci; $\mathrm{P} \%=$ percentage of polymorphic loci.

\section{Genetic diversity analysis}

The $N_{\mathrm{A}}, N_{\mathrm{E}}, H$, and $I$ values were estimated for different Vitis species (Table 3). For accessions numbers less than 1, the parameters were zero. For the other 13 species, $N_{\mathrm{A}}$ ranged from $1.1158(\mathrm{O})$ to $1.5483(\mathrm{~B})$, with an average value of 1.3009. $N_{\mathrm{E}}$ varied from $1.1158(\mathrm{O})$ to 1.2991 (B), with an average value of 1.2021. $H$ ranged from 0.0579 (O) to 0.1804 (B), with an average value of 0.1144 . I varied from 0.0803 (O) to 0.2752 (B), with an average value of 0.1686 . The maximum $H(0.1804)$ and $I(0.2752)$ values among the different species in B indicated that it was genetically more diverse than the other species.

For the 4 major ecogeographic regions, the $H$ and $I$ values increased from R4 to R1, R3, and R2 (Table 4), this trend showing that the genetic diversity of the 4 regions varied. 


\begin{tabular}{|c|c|c|c|c|c|}
\hline Pop. code & Acc. No. & $N_{\mathrm{A}}$ & $N_{\mathrm{E}}$ & $H$ & $I$ \\
\hline $\bar{A}$ & 2 & 1.1390 & 1.1390 & 0.0695 & 0.0963 \\
\hline B & 9 & 1.5483 & 1.2991 & 0.1804 & 0.2752 \\
\hline $\mathrm{C}$ & 1 & & & & \\
\hline D & 1 & & & & \\
\hline E & 2 & 1.1737 & 1.1737 & 0.0869 & 0.1204 \\
\hline F & 8 & 1.4093 & 1.2495 & 0.1464 & 0.2193 \\
\hline G & 12 & 1.3822 & 1.1684 & 0.1075 & 0.1698 \\
\hline $\mathrm{H}$ & 7 & 1.3282 & 1.1992 & 0.1182 & 0.1773 \\
\hline I & 5 & 1.3089 & 1.2013 & 0.1186 & 0.1759 \\
\hline $\mathrm{J}$ & 5 & 1.3514 & 1.2400 & 0.1389 & 0.2044 \\
\hline K & 2 & 1.2162 & 1.2162 & 0.1081 & 0.1499 \\
\hline $\mathrm{L}$ & 2 & 1.1969 & 1.1969 & 0.0985 & 0.1365 \\
\hline M & 1 & & & & \\
\hline $\mathrm{N}$ & 1 & & & & \\
\hline $\mathrm{O}$ & 2 & 1.1158 & 1.1158 & 0.0579 & 0.0803 \\
\hline $\mathrm{P}$ & 1 & & & & \\
\hline Q & 7 & 1.3205 & 1.1953 & 0.1157 & 0.1734 \\
\hline $\mathrm{R}$ & 10 & 1.4208 & 1.2330 & 0.1404 & 0.2135 \\
\hline $\mathrm{S}$ & 1 & & & & \\
\hline $\mathrm{T}$ & 1 & & & & \\
\hline
\end{tabular}

Table 4. Parameter of genetic diversity of 4 major ecogeographic regions for Chinese wild Vitis species.

\begin{tabular}{lcccc}
\hline Origin & $N_{\mathrm{A}}$ & $N_{\mathrm{E}}$ & $H$ & $I$ \\
\hline $\mathrm{R} 1$ & 1.5714 & 1.2986 & 0.1805 & 0.2769 \\
$\mathrm{R} 2$ & 1.7220 & 1.3119 & 0.1947 & 0.3067 \\
$\mathrm{R} 3$ & 1.7490 & 1.2884 & 0.1834 & 0.2925 \\
$\mathrm{R} 4$ & 1.1395 & 1.1310 & 0.1165 & 0.1559 \\
\hline$N_{\mathrm{A}}=$ observed number of alleles; $N_{\mathrm{E}}=$ effective number of alleles; $H=$ Nei's gene diversity; $I=$ Shannon information \\
index.
\end{tabular}

According to the Nei analysis of gene diversity, genetic differentiation and gene flow existed for different Vitis species. The values of genetic differentiation and gene flow were estimated to be 0.6570 and 0.2610 , respectively.

\section{Cluster analysis}

The UPGMA dendrogram obtained from the SSR and SRAP data is shown in Figure 1. UPGMA grouped the 80 Vitis accessions into 3 main clusters (Figure 2). Cluster 1 comprised a single species ( $V$. quinquangularis). Cluster 2 comprised 55 Vitis accessions that were further divided into 6 subclusters. Within Cluster 2, the first subcluster consisted of a single species ( $V$. pseudoreticulata). The second subcluster also contained a single species $(V$. amurensis). The third subcluster consisted of V. yeshanensis, Vitis spp (Qiufuyie), V. piasekii, $V$. bashanica, $V$. liubaensis, $V$. romanetii, and $V$. baihensis. The fourth subcluster contained $V$. davidii and $V$. riparia. The fifth subcluster comprised a single species ( $V$. adstricta). The sixth subcluster contained Vitia sp, V. qinlingensis, V. hancockii, and V. ficifolia. Cluster 3 was composed of 18 accessions, and all American and European cultivars were in this cluster, along with Chinese wild Vitis accession Wanxian-15. 


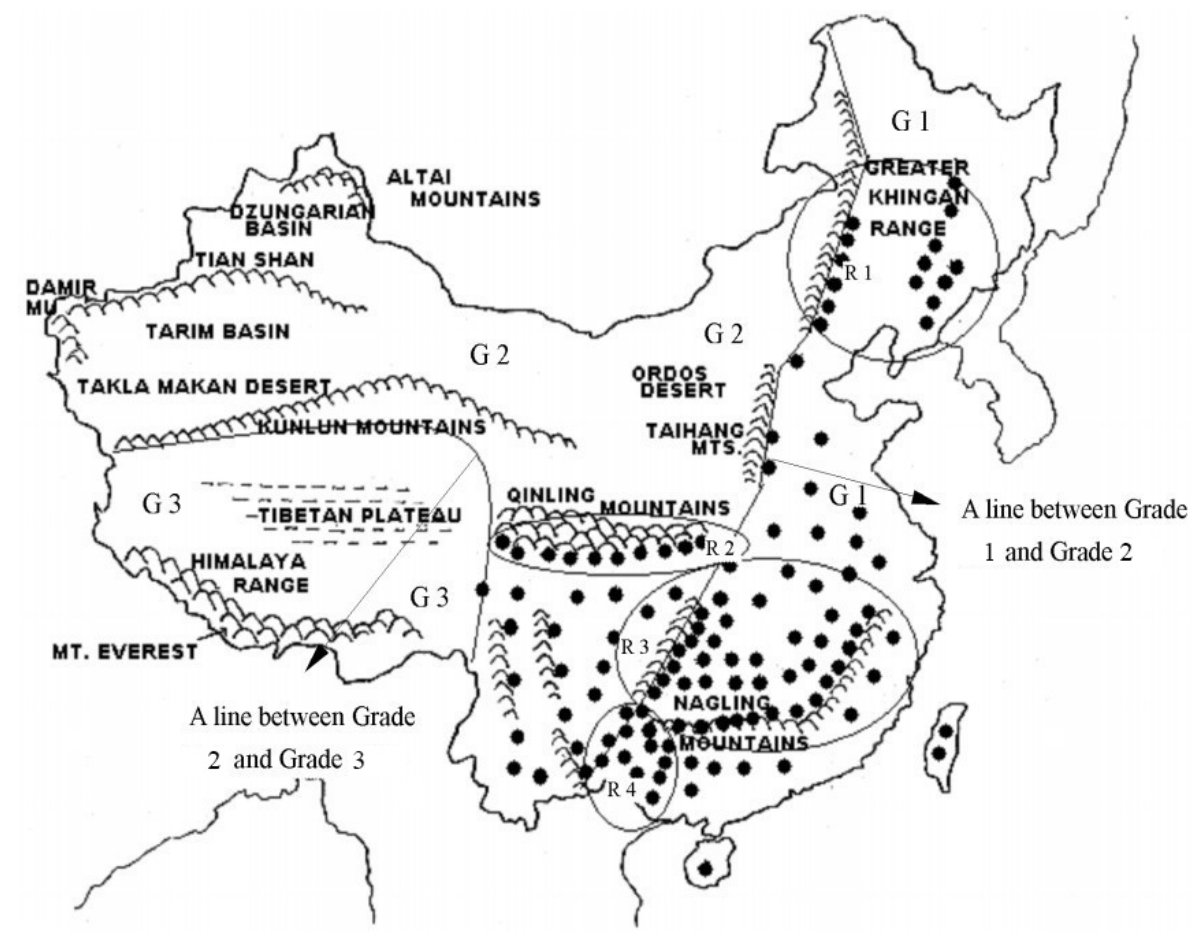

Figure 1. Map showing wild grapes distributed in China (from Wan et al., 2008). R1, R2, R3, R4: 4 major ecogeographic regions of Chinese wild grape distribution. R1 = Changbaishan and Xiaoxing'anling Mountain regions; R2 = Qinling Mountain region; R3 = Yangtze River region; R4 = Guangxi region. Circles or ellipses in the map representing the 4 major ecogeographic regions of Chinese wild grapes are mainly distributed.

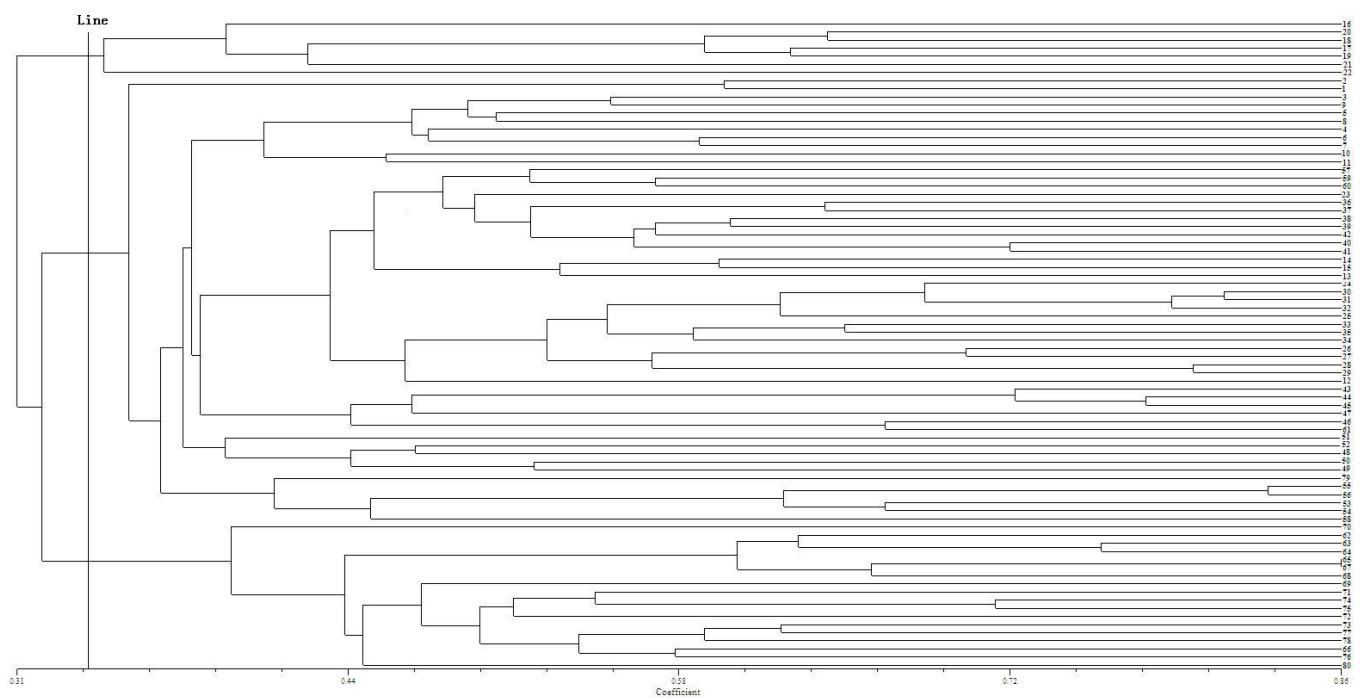

Figure 2. Unweighted pair-group method with arithmetic average dendrogram of the 80 Vitis constructed using the genetic similarity analysis based on SSR and SRAP analysis. 


\section{Principal coordinate analysis}

PCoA further helped in describing the variability among these accessions in a 2-dimensional model. PCoA data based on the genetic similarity matrix are shown in Figure 3. The PCoA analysis indicated that the first and the second principal components accounted for 19.01 and $14.18 \%$ of the total variation (Figure 3), respectively. The classification of all accessions derived from PCoA was similar to the result of the UPGMA analysis.

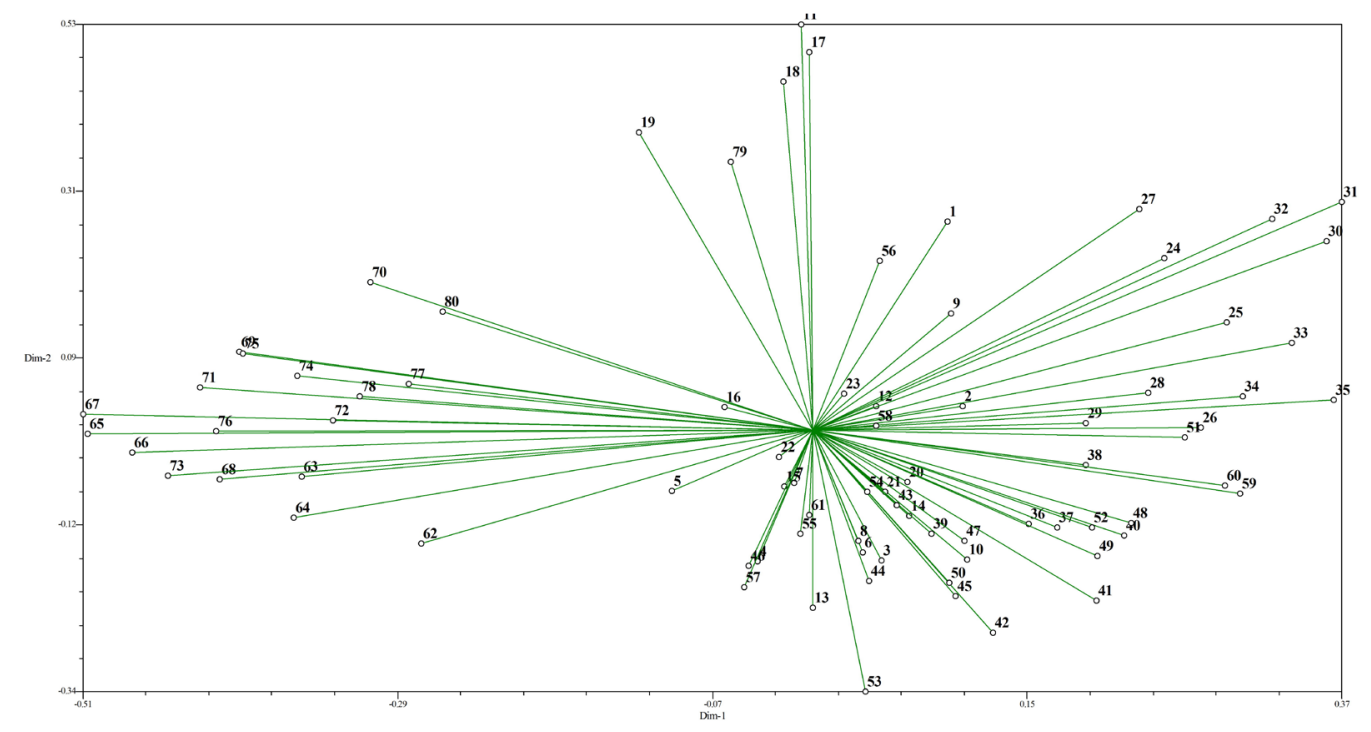

Figure 3. Relationships among the 80 Vitis by principal coordinate analysis based on SSR and SRAP data.

\section{Analysis of Nei's genetic identity and genetic distance among different species}

The Nei genetic identity and the genetic distance among different species were analyzed using the POPGENE software (data not shown). Based on the genetic distance, the dendrogram of 20 species was constructed using the MEGA software (Figure 4). The genetic identity ranged from 0.6988 to 0.9563 . The highest genetic identity was between $V$. davidii and $V$. qinlingensis, and the lowest was between $V$. bashanica and $V$. ficifolia. The genetic distance ranged from 0.0447 to 0.3639 . Among Chinese wild Vitis species, the largest genetic distance was found between $V$. ficifolia and the other wild species.

\section{DISCUSSION}

\section{SSR and SRAP markers}

DNA markers are powerful and reliable tools for evaluating the genetic diversity of plants. SSR and SRAP are efficient molecular marker systems that have been used to assess 
genetic diversity in different plants (Brini et al., 2008; Erfani et al., 2012; Guo et al., 2012b). SSR and SRAP markers amplify the different parts of the genome. SSR marker amplification targets are the simple sequence repeats, which include microsatellite DNA. However, SRAP marker amplification targets are located in the open reading frame, which includes the intron(s) and promoter region. Therefore, SRAP markers could better reflect the diversity of the plants. SSR and SRAP markers have been successfully applied to some wild and cultivated plants; however, for more than 18 Chinese wild Vitis species, the application of the SSR and SRAP combined markers has been scarce. In this study, SSR and SRAP markers were used to evaluate the genetic diversity among 18 Chinese wild grape and varieties from America and Europe. The average polymorphic band amplified by each primer was 12.38 , and the percentage of polymorphic loci reached $97.02 \%$. This result is highly comparable to the one described by Luo et al. (2001), who reported a 68.7\% polymorphism level in 83 similar wild Chinese Vitis clones or accessions using RAPD markers. Polymorphism levels also suggest that SSR and SRAP combined markers is an effective tool for identifying genetic diversities of wild Vitis species native to China, and to separate Chinese wild Vitis from American and European cultivars.

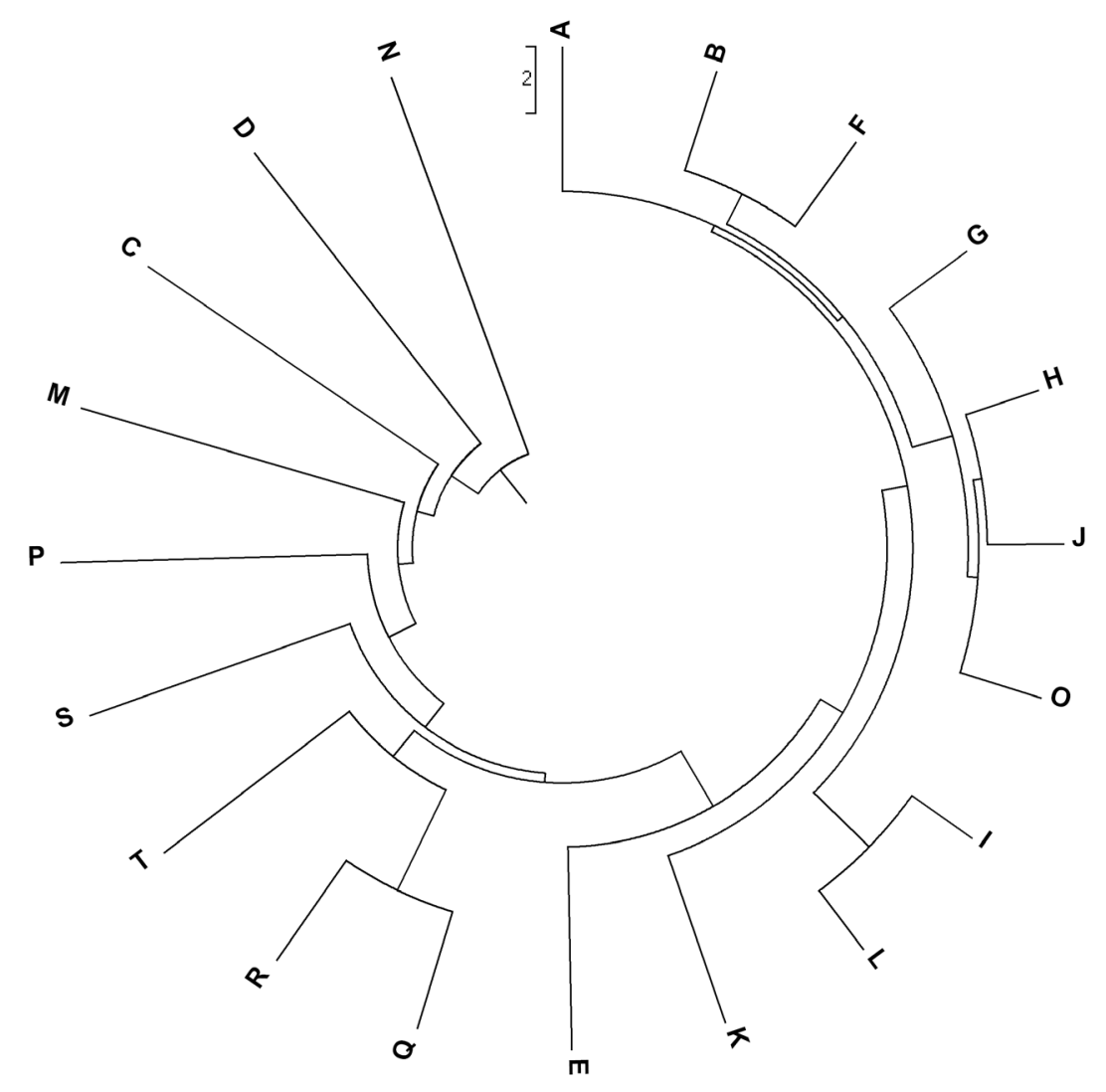

Figure 4. Dendrogram showing genetic relationships among grape species from 4 major ecogeographic regions by the MEGA software. The species numbers are the same as those listed in Table 1. 


\section{Genetic diversity and cluster analysis}

The abundant genetic diversity of Chinese wild Vitis species in different ecogeographic regions has resulted from many causes, including climatic, ecologic, and geographic factors, and cultivation history. Chinese wild Vitis species are found predominantly in the Qinling Mountains and the Bashan Mountains, and the Jiangxi, Hubei, and Hunan Provinces have relatively high diversity, with over 30 species found in these areas (Wan et al., 2008). In this study, the genetic diversities of Chinese wild Vitis species from R2 $(H=0.1947, I=$ $0.3067)$ and $\mathrm{R} 3(H=0.1834, I=0.2769)$ were higher. These results are consistent with those of Wan et al. (2008). The ecogeographic regions R2 and R3 comprised the Shaanxi, Henan, Gansu, Hunan, Jiangxi, Zhejiang, Hubei, Anhui, Jiangsu, and some of Shanghai Provinces. The temperature, annual rainfall, and soil are suitable for grape growth, and thus these regions have a higher Vitis diversity (He, 1999b; Kong, 2004).

Genetic similarity values among all the 80 grape accessions ranged from 0.31 to 0.86 , which showed a high genetic diversity among these Vitis accessions. The classification of a few Chinese Vitis species adopted by Chinese taxonomists has some controversy and confusion. Whether $V$. ficifolia is a subspecies of $V$. quinquangularis or a separate species is still being disputed (Kong, 2004). In this study, the largest genetic distance was found between $V$. ficifolia and the other wild species, and the relationship between $V$. ficifolia and $V$. quinquangularis was distant (Figure 4); therefore, our result agrees with that of Wang (1979) in that V. ficifolia could be considered a separate species. Through morphological trait analysis, He et al. (1996) found that a close relationship existed between $V$. yeshanensis and $V$. amurensis, and $V$. yeshanensis was considered to be a variety of $V$. amurensis (Lu and Liang, 1993). However, the leaf and shoot morphologies as well as drought tolerance and cold hardiness of $V$. yeshanensis are different from those of $V$. amurensis, suggesting that it may be a separate species (Niu and He, 1996; He, 1999a). In the present study, a large distance was found between $V$. yeshanensis and $V$. amurensis (Figure 4), supporting the view that $V$. yeshanensis is a separate species.

In this study, SSR and SRAP markers classified studied accessions into different species (Figure 2); for example, Huaxian-11 was clustered into V. piasekii. The reasons were that interspecific hybridization and gene introgression had probably been involved in the evolution and conservation of the various species (Bell and Hough, 1986). This was also confirmed by the gene flow $\left(N_{\mathrm{m}}=0.2610\right)$ among different Vitis species.

\section{Theoretical significance for Chinese wild Vitis germplasm and breeding}

The evaluation and conservation of wild grape germplasms are important for grape breeding programs. Chinese wild Vitis species have been used in breeding program. For example, $V$. amurensis, V. quinquangularis, and $V$. davidii are the most widely used wild Vitis species for breeding in China, the United States, and Germany (He, 1999a). Large genetic variations could provide the opportunity to select and breed new varieties with adaptability to different environments (Hummer and Sugar, 1998). According to the previous and present results, there is a high degree of genetic diversity in Chinese wild Vitis species. Results indicated that parent materials of grape breeding could be selected from the Chinese wild grape species mentioned in this paper, and the genetic distance of parents should be considered first, whereas geographic distance is not important. Furthermore, it is necessary to reinforce the collection and protection 
of wild grape germplasm resources from ecogeographic regions with higher diversity, such as the Qinling Mountains region and the mid-downstream Yangtze River region.

\section{ACKNOWLEDGMENTS}

Research supported by the National Natural Science Foundation of China (\#31071782), the 948 Project from Ministry of Agriculture of China (\#2012-S12), and the Chinese Universities Scientific Fund (\#QN2011056).

\section{REFERENCES}

Bell RL and Hough LF (1986). Interspecific and intergeneric hybridization of Pyrus. Hort. Sci. 21: 62-64.

Brini W, Mars M and Hormaz JI (2008). Genetic diversity in local Tunisian pears (Pyrus communis L.) studied with SSR markers. Sci. Hortic. 115: 337-341.

Ercisli S, Orhan E, Hizarci Y, Yildirim N, et al. (2008). Genetic diversity in grapevine germplasm resources in the Coruh valley revealed by RAPD markers. Biochem. Genet. 46: 590-597.

Erfani J, Ebadi A, Abdollahi H and Fatahi R (2012). Genetic diversity of some pear cultivars and genotypes using simple sequence repeat (SSR) markers. Plant. Mol. Biol. Rep. 30: 1065-1072.

Guo DL, Zhang JY and Liu CH (2012a). Genetic diversity in some grape varieties revealed by SCoT analyses. Mol. Biol. Rep. 39: 5307-5313.

Guo DL, Zhang JY, Liu CH, Zhang GH, et al. (2012b). Genetic variability and relationships between and within grape cultivated varieties and wild species based on SRAP markers. Tree Genet. Genomes 8: 789-800.

He PC (1999a). Viticulture. China Agriculture Press, Beijing.

He PC (1999b). Wild Grape Resources; their Utilization in China. Sino-Overseas Grapevine Wine. Special Volume. 1-5.

He PC, Wang YJ, Wang GY, Ren ZB, et al. (1991). The studies on the disease-resistance of Vitis wild species originated in China. Sci. Agric. Sin. 24: 50-56.

He YH, Li CL and Cao YL (1996). Comparative anatomy of vegetative organs in the genus Vitis L.; its systematic significance. Chinese J. Appl. Environ. Biol. 2: 234-253.

Hummer KE and Sugar D (1998). Pear gene bank information on world-wide web. Acta Hort. 475: 117-121.

Kong QS (2004). Flora of Chinese Grapes. China Agriculture and Technology Press, Beijing.

Li JM and He PC (2000). Study on Important Wine Making Quality Character of Chinese Wild Vitis. Sci. Agric. Sin. 33: $17-23$.

Lu DZ and Liang HP (1993). A new species of Vitis. J. Beijing For. Univ. 15: 134.

Luo SL, He PC, Zheng XQ and Zhou P (2001). Genetic diversity in wild grapes native to China based on randomly amplified polymorphic DNA (RAPD) analysis. Acta Bot. Sin. 43: 158-163.

Ma ZS and He PC (1998). A study on the taxonomy and relationship of wild Vitis native to China with POD isozyme. Acta Agricult. Boreali-Sin. 13: 122-126.

Nei M (1978). Estimation of average heterozygosity and genetic distance from a small number of individuals. Genetics 89: 583-590.

Niu LX and He PC (1996). Taxonomy classification of Chinese wild Vitis plants. Acta Hortic. Sin. 23: 209-212.

Qu X, Lu J and Lamikanra O (1996). Genetic diversity in Muscadine and American bunch grapes based on randomly amplified polymorphic DNA (RAPD) analysis. J. Am. Soc. Hort. Sci. 121: 1020-1023.

Rohlf FJ (2000). NTSYS-pc: Numerical Taxonomy and Multivariate Analysis System. Version 2.1. Exeter Software, Setauket.

Tamura K, Dudley J, Nei M and Kumar S (2007). MEGA4: Molecular Evolutionary Genetics Analysis (MEGA) software version 4.0. Mol. Biol. Evol. 24: 1596-1599.

Wan YZ, Schwaninger HDL, Simon CJ, Wang YJ, et al. (2008). A review of taxonomic research on Chinese wild grapes. Vitis 47: 81-88.

Wang WT (1979). Vitacearum novitiates. Acta Phytotax. Sin. 17: 73-96.

Wang XP, Wang Y, Zhang CH and Zhang J (2007). Isolation and characterization of cDNA encoding stilbene synthases from Chinese wild Vitis pseudoreticulata. Vitis 46: 104-109.

Wang Y, Liu Y, He P, Chen J, et al. (1995). Evaluation of foliar resistance to Uncinula necator in Chinese wild Vitis species. Vitis 34: 159-164. 
Yeh FC, Yang RC and Boyle T (1999). POPGENE. Microsoft Windows-Based Freeware for Population Genetic Analysis. Release 1.31. University of Alberta, Edmonton.

Zhu L, Wen XY and Li WW (1994). Studies on Photosynthetic Characteristic of a Chinese Wild Species Grapevine. Acta Hortic. Sin. 21: 31-34. 